\title{
Selected properties of galvanic coatings shaped using thermal drilling technology
}

\author{
Waldemar Matysiak ${ }^{1,}$, Dariusz Bartkowski ${ }^{1}$, and Aneta Bartkowska ${ }^{2}$ \\ ${ }^{1}$ Poznan University of Technology, Faculty of Mechanical Engineering and Management, Institute of \\ Materials Technology, Poznan, Poland \\ ${ }^{2}$ Poznan University of Technology, Faculty of Mechanical Engineering and Management, Institute of \\ Materials Science and Engineering, Poznan, Poland
}

\begin{abstract}
The paper presents the investigations of mechanical properties and microstructure of materials formed by thermal drilling process (Flow drill). The aim of this study was to determine the microstructure of the surface layers produced using galvanic method on the low-carbon steel after formed this layer using thermal drilling technology. The coatings of copper and nickel thicknesses of 5,10 and $15 \mu \mathrm{m}$ were applied. Microstructure, chemical composition and microhardness was study. It was found the possibility of forming galvanic coatings using thermal drilling technology and change in chemical composition of treated material.
\end{abstract}

\section{Introduction}

At present, the requirements for the construction of tools and machine parts are increasing. Therefore, the search for new technological and material solutions is inevitable and becomes the goal of many researchers [1 - 7]. In order to make good connections, both detachable and inseparable, not only must the material have specific properties but also the processing technology used must provide the highest quality end product. To achieve specific requirements, it is advisable to improve the properties of the material using various enhancements. These can include, but are not limited to, surface modifications of the material by creating a new surface layer with unique properties that could not be obtained using the substrate material. Surface engineering technologies [4 - 8] also affect other technologies, such as plastic processing [3, 8 - 18]. One of the processes of plastic working is the hole flanging process, which is intended to increase the diameter of the previously cut hole and to form the material around as a conical or cylindrical flange. There are several ways to do this in different sources. One of them is flanging through the cylindrical punch with a tapered end which is supposed to pierce through the material by punch, and then form a corresponding hole shape and a flange around it. A major disadvantage of this method is the poor quality of the flange. There is also a technology for the hole flanging process through the thermal drilling (Flow drill). This is a method of producing flange holes without chip. Using this process, during contact of the tool with the workpiece, due to the

\footnotetext{
${ }^{*}$ Corresponding author: waldemar.matysiak@put.poznan.pl
} 
high vertical force and the heat generated by the rotation and friction, the material is plasticised. This makes the conical part of the tool squeeze through the material and forming a hole. In the further part of the process, two fins are created: the top, from which the flange can be formed, and the bottom, which is shaped of sleeve. After shaping the flange of hole, the tool is retracted and the element cooled down in the air. The process takes place at very high speeds $[8,10,12]$.

This work focuses on the flanging hole process of the elements with the galvanized coating. Flow drill technology is used in this research, which is significantly different from the classic methods of flanging. Selected features such as macro- and microstructure, coating thickness, microhardness, and chemical composition of the produced were investigated and results were analysed.

\section{Research Methodology}

\subsection{Materials and technology}

The starting material used for the hole flanging process was the general purpose structural S235JRH steel. The chemical composition of this material was shown in Table 1, and mechanical properties were shown in Table 2.

Table 1. Chemical composition of S235JRH steel used for testing.

\begin{tabular}{|c|c|c|c|c|c|}
\hline \multirow{2}{*}{ Steel grade } & \multicolumn{5}{|c|}{ Maximum weight share [\%] } \\
\cline { 2 - 6 } & $\mathrm{C}$ & $\mathrm{Mn}$ & $\mathrm{P}$ & $\mathrm{S}$ & $\mathrm{N}$ \\
\hline $\mathrm{S} 235$ & 0.17 & 1.40 & 0.045 & 0.045 & 0.009 \\
\hline
\end{tabular}

Table 2. Selected properties of S235 steel used for testing.

\begin{tabular}{|c|c|c|c|}
\hline Steel grade & $\begin{array}{c}\text { Yield strength } \\
\mathrm{R}_{\mathrm{eH}}\left[\mathrm{N} / \mathrm{mm}^{2}\right]\end{array}$ & $\begin{array}{c}\text { Tensile strength } \\
\mathrm{R}_{\mathrm{m}}\left[\mathrm{N} / \mathrm{mm}^{2}\right]\end{array}$ & $\begin{array}{c}\text { Minimal } \\
\text { elongation } \mathrm{A}_{5}[\%]\end{array}$ \\
\hline $\mathrm{S} 235$ & 235 & 360 & 20 \\
\hline
\end{tabular}

Specimens of $30 \times 24 \times 20 \mathrm{~mm}$ with a wall thickness of $2 \mathrm{~mm}$ were cut from the profile, and next were galvanized. Nickel plating and galvanic copper plating were performed. Nickel plating was carried out by chemical deposition in a bath consisting of nickel chloride, sodium hypophosphite and sodium acetate. The bath temperature was equal to 60 ${ }^{\circ} \mathrm{C}$. Copper plating was carried out in the acid bath (sulphate) composed of copper sulphate and sulphuric acid. The bath temperature was $38{ }^{\circ} \mathrm{C}$, while the current density was $2 \mathrm{~A} / \mathrm{dm}^{2}$. These parameters were shown in Table 3.

Table 3. Parameters of galvanic treatment.

\begin{tabular}{|c|c|c|c|c|c|c|}
\hline Galvanic treatment & \multicolumn{3}{|c|}{ Nickel-plating } & \multicolumn{3}{|c|}{ Copper-plating } \\
\hline Temperature $\left[{ }^{\circ} \mathrm{C}\right]$ & \multicolumn{3}{|c|}{60} & \multicolumn{3}{|c|}{38} \\
\hline Current density $\left[\mathrm{A} / \mathrm{dm}^{2}\right]$ & \multicolumn{3}{|c|}{-} & \multicolumn{3}{|c|}{2} \\
\hline Time $[\mathrm{h}]$ & 3 & 6 & 9 & 0.5 & 1 & 1.5 \\
\hline Average coating thickness $[\mu \mathrm{m}]$ & 5 & 10 & 15 & 5 & 10 & 15 \\
\hline
\end{tabular}

Specimens with galvanized coating were subjected to a flow drill process. Holes and flanging for each specimen were made on a JET JMD-18VS drilling machine. The machine 
was equipped with a handle with an aluminium cooling ring in which a drill bit of $7.3 \mathrm{~mm}$ was mounted. The tool was secured with a Flow drill FDKS paste that was applied each time before the hole was made to protect the tool from high temperatures. Tools turnover amounted to $3000 \mathrm{rev} / \mathrm{min}$, and feed rate was performed manually. Figure 1 shows a scheme of the hole flanging process in materials with a galvanized coating.
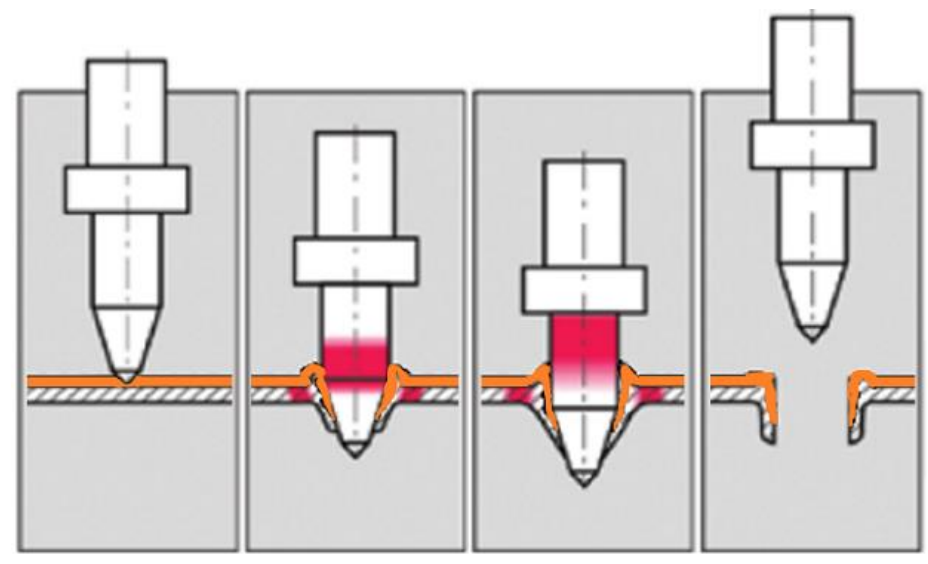

Fig. 1. Scheme of flanging using Flowdrill technology in materials with coating.

\subsection{Microstructure and microhardness study}

Macroscopic observation of individual specimens was performed using an unarmed eye and a magnifying glass. For each specimen, colour, cracks and porosity were determined. Photos were taken with the Nikon D3100. Microstructural observations were made using the Huvitz HRM-300 microscope. For the tests, metallographic cross section sewer made, which were prepared by cutting the specimens and placing them in Buehler's Conduktomet conductive thermoset resin. To reveal the microstructure of specimen's substrate and its surface, nital was digested, which is a mixture of nitric acid and ethanol. The Axio Vision microscope software program from Carl Zeiss was used to investigate the thickness of coatings. Microhardness measurement were performed using the Vickers method on the Buehler microhardness tester.

\subsection{Chemical composition study}

The chemical composition of specimens was examined using a scanning electron microscope (SEM) equipped with PGS's Prism 2000 EDS (Energy Dispersive Spectroscopy) system. EDS analysers allow both surface and volumetric identification of the chemical elements contained in the test material. A linear analysis of the chemical composition was carried out for each specimen.

\section{Results of study}

\subsection{Microstructure and microhardness results}

In Figure 2 was shown macroscopic images of specimens made after the galvanic copper plating process. The process was carried out in such a way that the final thickness coatings 
was obtained 5, 10 and $15 \mu \mathrm{m}$. Good surface quality has been found after the coppering process. Stains created during the process do not belong to technical drawbacks of galvanic processes. In Figure 5 was shown macroscopic images of specimens after nickel plating on 5, 10 and $15 \mu \mathrm{m}$ thick. They were characterized by surface homogeneity.
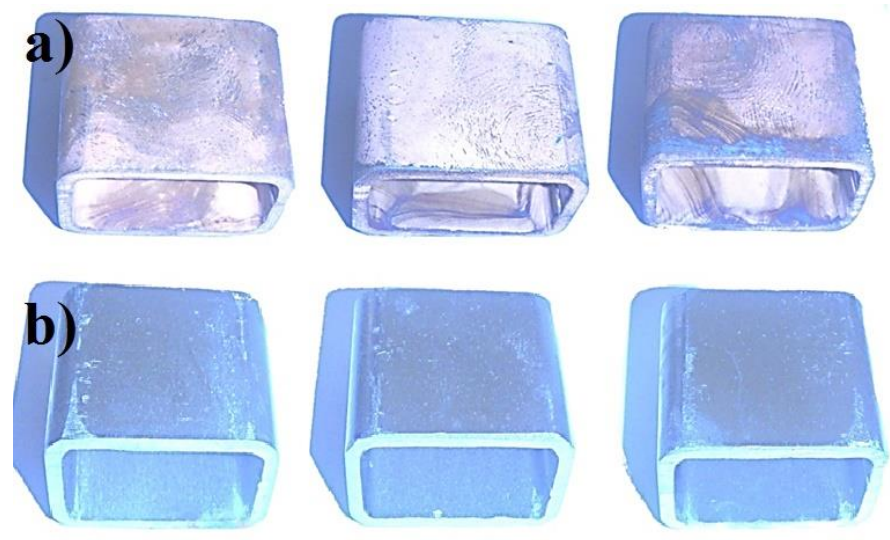

Fig. 2. Specimens after: a) galvanic copper plating, b) galvanic nickel plating with thickness of 5, 10 and $15 \mu \mathrm{m}$ (left to right).

The microhardness of the copper coating is about $154 \mathrm{HV}$ on average. During the study it was found that the application of the copper coating and its plastic shaping increased the microhardness of the inner side of the flange to over $300 \mathrm{HV}$. Microhardness measurement results are shown in Figure 3a. Microhardness of the nickel coating is about $400 \mathrm{HV}$ on average. However, it has been shown during the tests that the application of the nickel coating and its plastic shaping does not affect the hardening of the inner side of the flange. The hardness remains the same as the steel substrate. Micro hardness measurement results were shown in Figure 3b.

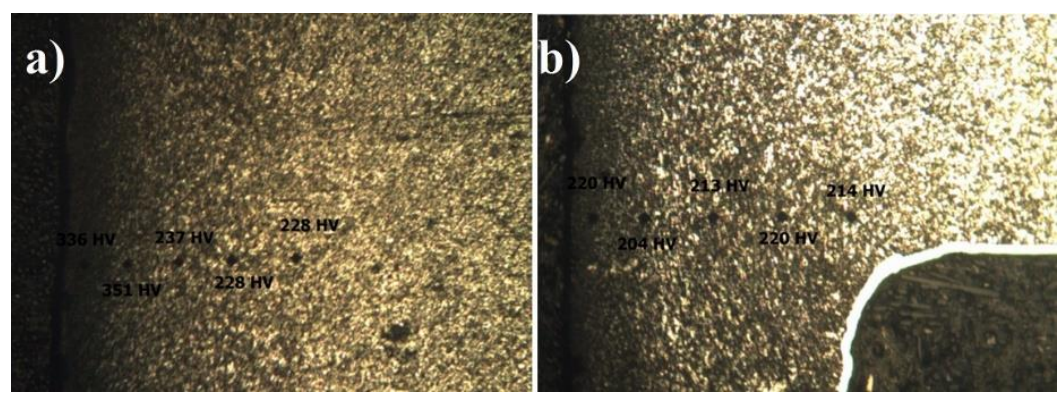

Fig. 3. Microhardness of the inner part of flange: a) after galvanized copper plating and Flow drill process, b) galvanized nickel plating and Flow drill process.

In Figures 4a-4c were shown the results of the microstructure study of galvanic copper coatings. It has been possible to shape copper galvanized products using Flow drill technology. The coating on the outside of the fold does not crack, but on the inside the copper modifies the substrate through diffusion processes. In Figures 5a-5c were shown the results of microstructural studies on nickel coatings. It has been possible to shape copper galvanized products using Flow drill technology. The coating on the outside of the fold did not crack at 5 and $10 \mu \mathrm{m}$ thick, but at $15 \mu \mathrm{m}$ thickness cracks were observed. On the inside, the nickel coating modifies the substrate through diffusion processes. 


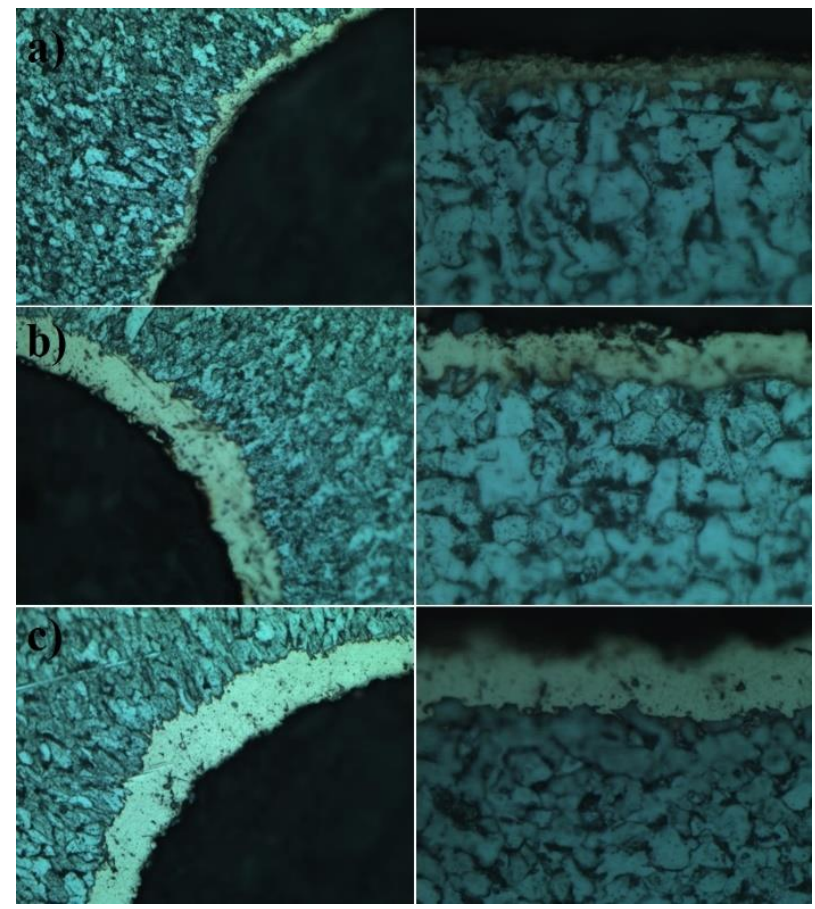

Fig. 4. Galvanic coating of copper having a thickness of : a) $5 \mu \mathrm{m}$, b) $10 \mu \mathrm{m}$, c) $15 \mu \mathrm{m}$ after flanging of hole edge; magnification: figure left $-100 x$, figure right $-500 x$.

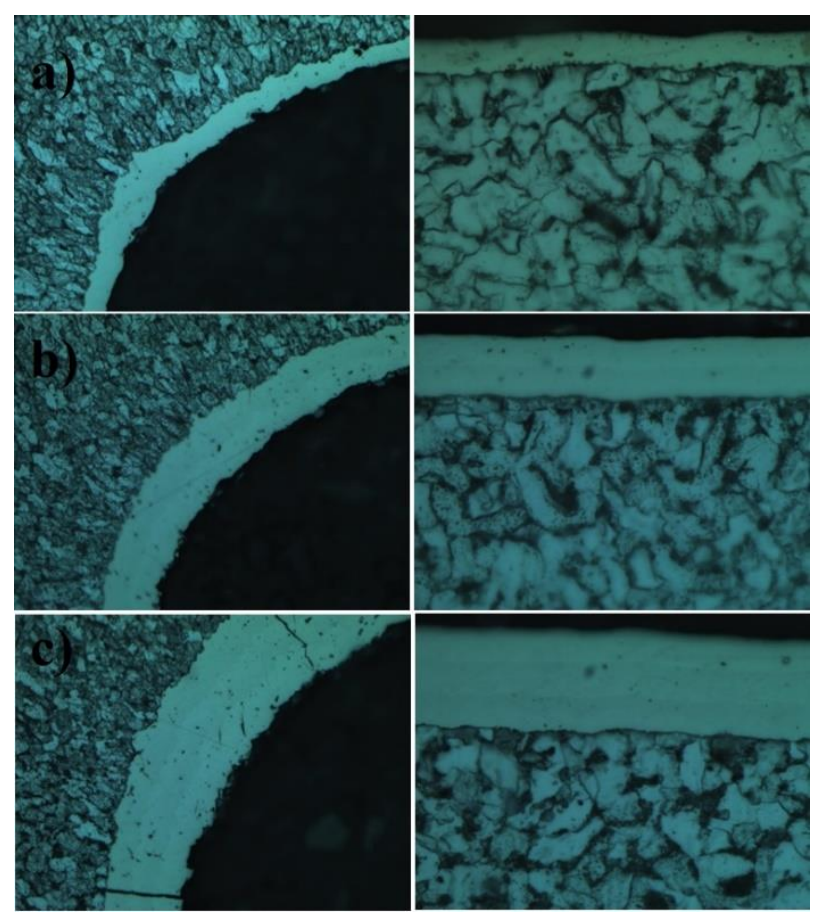

Fig. 5. Galvanic coating of nickel having a thickness of : a) $5 \mu \mathrm{m}$, b) $10 \mu \mathrm{m}$, c) $15 \mu \mathrm{m}$ after flanging of hole edge; magnification: figure left $-100 x$, figure right $-500 x$. 


\subsection{Chemical composition study}

Figure 6 shows a linear distribution of the chemical composition on specimen after galvanic copper plating process on thickness of $15 \mu \mathrm{m}$ and after Flow drill process. As can be seen, the copper coating during the thermoforming process has been mixed by diffusion with the steel substrate. It can be found that the coating was well adhered to the steel substrate and plastically shaped. Due to the increased temperature and friction the properties of the steel surface have been altered at the point of flanging on the inner side of the sleeve.
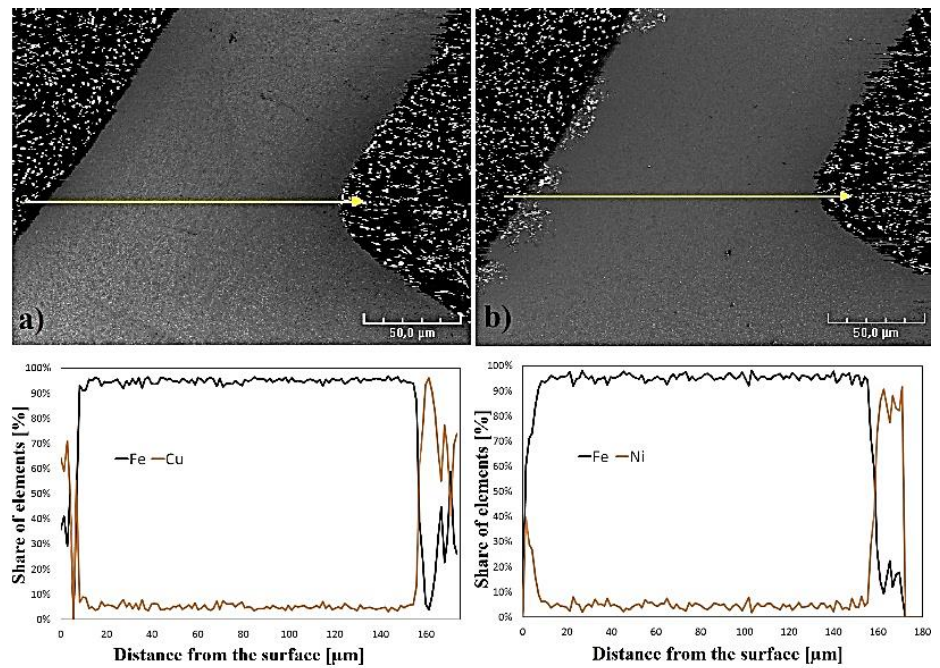

Fig. 6. Linear distribution of chemical composition after: a) galvanic copper and Flow drill process, b) galvanic nickel and Flow drill process.

Figure 15 shows a linear distribution of the chemical composition on a plated nickel plated sample with a $10 \mu \mathrm{m}$ film thickness under Flow drill. As can be seen, the nickel coating during the thermoforming process has been mixed by diffusion with a steel substrate. It can be stated that the nickel coating has not been abraded, but has been plastically shaped. Due to elevated temperatures and friction, the steel surface properties of the rolled steel surface have been altered on the inside of the sleeve.

\section{Conclusions}

Based on the presented studies it was possible to perform the thermoforming process in materials with the produced surface layers in the form of galvanic coatings. General work requests are presented below:

- There is the possibility of plastic forming of steel with galvanic coatings using Flow drill technology

- The thickness of the surface layers produced significantly influences the possibility of their shaping by thermal drilling. Thicker coatings of nickel are more prone to cracking. Copper coatings do not tend to crack during shaping.

- Flow drill process on galvanic coatings modifies the steel surface. The chemical composition of the inner part of the hole flange was changing.

The method described in this paper may be used in the case of joining materials with coatings for example, if the galvanic coatings already existed on the jointed products, or if no other connection is possible e.g. by welding. 


\section{References}

1. L. Sobotová, Transfer inovácií (in Slovak) 10, 144-148 (2007)

2. L.Sobotová, E. Spišák, Automotive industry magazine (in Slovak) 2, $62-64$ (2009)

3. W. Matysiak, L. Bernat, Metalurgija 54, 235-238 (2015)

4. D. Bartkowski, A. Młynarczak, A. Piasecki, B. Dudziak, M. Gościański, A. Bartkowska, Opt Laser Technol 68, 191-201 (2015)

5. A. Bartkowska, A. Pertek, M. Jankowiak, K. Jóźwiak, Arch Metall Mater. 57, 211-214 (2012)

6. A. Bartkowska, A. Pertek, Surf Coat Tech 248, 23-29 (2014)

7. D. Bartkowski, A. Bartkowska, IJRMHM 64, 20-26 (2017)

8. S. Zhou, X. Dai, H. Zheng, Opt Laser Technol 44, 190-197 (2012)

9. T. Baidridge, G. Poling, E. Foroozmehr, V. Kadekar, M.C. Gupta, Opt. Lasers Eng. 51, 180-184 (2013)

10. S. Zhou, Y. Huang, X. Zeng, Appl Surf Sci 254, 3110-3119 (2008)

11. S.M. Zhu, Y.D. Zhang, Appl. Mech.Mater 556-562, 189-192 (2014)

12. Q. Ma, Y. Li, J.Wang, K. Liu, Mater Des 92, 897-905 (2016)

13. W. Matysiak. D. Bartkowski, M. Hatala, J. Zajac, S. Radhenko, R. Cep, Key Engineering Materials 669, 87-94 (2016)

14. W. Matysiak, Metal forming 4, 49-57 (2005)

15. W. Matysiak, B. Barišić, I. Mamuzić, Metabk 49, 13-17 (2010)

16. S. Dobatkin, J. Zrnik, I. Mamuzic, Metalurgija 48, 157-160 (2009)

17. H.-M. Chow, S.-M. Lee, L.-D. Yang, J Mater Process Tech 207, 180-186 (2008)

18. S. F. Miller, J. Tao, A. J. Shih, Int J Mach Tool Manu 46, 1526-1535 (2006) 
